\title{
Role of ascorbic acid in promoting follicle integrity and survival in intact mouse ovarian follicles in vitro
}

\author{
A. A. Murray ${ }^{1}$, M. D. Molinek ${ }^{1}$, S. J. Baker ${ }^{1}$, F. N. Kojima², \\ M. F. Smith², S. G. Hillier ${ }^{3}$ and N. Spears ${ }^{1 *}$ \\ ${ }^{1}$ Department of Biomedical Sciences, Hugh Robson Building, University of Edinburgh, \\ George Square, Edinburgh EH8 9XD, UK; ${ }^{2}$ Animal Sciences Unit, University of Missouri- \\ Columbia, 160 Animal Sciences Center, Columbia, MO 65211, USA; and ${ }^{3}$ Department of \\ Reproductive and Developmental Sciences, University of Edinburgh, Chalmers Street, \\ Edinburgh EH3 9EW, UK
}

Ascorbic acid has three known functions: it is necessary for collagen synthesis, promotes steroidogenesis and acts as an antioxidant. Within the ovary, most studies have concentrated on the role of ascorbic acid in luteal formation and regression and little is known about the function of this vitamin in follicular growth and development. Follicular growth and development were investigated in this study using an individual follicle culture system that allows the growth of follicles from the late preantral stage to Graafian morphology. Follicles were isolated from prepubertal mice and cultured for 6 days. Control media contained serum and human recombinant FSH. Further groups of follicles were cultured in the same media but with the addition of ascorbic acid at concentrations of either 28 or $280 \mu \mathrm{mol} \mathrm{I}^{-1}$. Addition of ascorbic acid at the higher concentration significantly increased the percent- age of follicles that maintained basement membrane integrity throughout culture $(P<\mathbf{0 . 0 0 1})$. Ascorbic acid had no effect on the growth of the follicles or on oestradiol production. Metalloproteinase 2 activity tended to increase at the higher concentration of ascorbic acid and there was a significant concomitant increase in the activity of tissue inhibitor of metalloproteinase 1 $(P<0.01)$. Follicles cultured without the addition of serum but with FSH and selenium in the culture media underwent apoptosis. Addition of ascorbic acid to follicles cultured under serum-free conditions significantly reduced apoptosis $(\boldsymbol{P}<\mathbf{0 . 0 5})$. From these data it is concluded that ascorbic acid is necessary for remodelling the basement membrane during follicular growth and that the ability of follicles to uptake ascorbic acid confers an advantage in terms of granulosa cell survival.

\section{Introduction}

The actions of ascorbic acid (vitamin C) are among the best understood of all the vitamins. Ascorbic acid is a dietary requirement for primates, and a few other mammals, which lack the necessary hepatic enzymes for its synthesis. This vitamin has been associated with conditions such as ageing, the common cold and cancer, and the recommended daily requirement has been the subject of many debates.

The ovaries, and other endocrine tissues, accumulate large amounts of ascorbic acid. Within the ovaries, ascorbic acid accumulates in the granulosa, thecal and luteal cells (Deane, 1952) and it has long been associated with fertility (Luck et al., 1995). Ascorbic acid has been used to treat infertility in cows (Phillips et al., 1941) and enhances the effect of clomiphene on induction of ovulation in women (Igarashi, 1977). Conversely, high dosages have

*Correspondence

Email: Norah.Spears@ed.ac.uk been implicated in spontaneous abortion in both women and rats (Samborskaia and Ferdman, 1966). The ovarian content of ascorbic acid changes throughout the oestrous cycle. In response to the $\mathrm{LH}$ preovulatory surge, ascorbic acid uptake by the ovaries is blocked and tissue content is depleted: an action that formed the basis of an early bioassay (Parlow, 1958). Ovaries produce increasing concentrations of progesterone in response to LH. Studies on luteinizing granulosa cells have shown that ascorbic acid stimulates production of progesterone (Byrd et al., 1993) and that increasing progesterone concentrations block the uptake of ascorbic acid (Stansfield and Flint, 1967). Therefore, the action of LH may indirectly control the fluctuations in ascorbic acid concentration observed throughout the ovarian cycle. In addition, ascorbic acid acts as a co-factor in the amidation of some proteins and has been implicated in the regulation of oxytocin secretion by ovaries (Luck and Junglas, 1987).

The role of ascorbic acid in promoting collagen biosynthesis has been studied extensively (Pinnell, 1985). During follicular growth, ovulation and formation of corpora lutea, basement membranes and the extracellular matrix 
are undergoing constant remodelling and, therefore, have high requirements for collagen. Early studies implicated ascorbic acid in the regulation of the Graafian follicular basement membrane; lack of ascorbic acid causes degeneration of follicle membranes and high doses inhibit collagenolytic activity in mature follicles (Kramer et al., 1933; Espey and Coons, 1976).

The matrix metalloproteinases (MMPs) and their inhibitors, tissue inhibitors of metalloproteinases (TIMPS), are members of an enzyme family associated with the remodelling of extracellular matrix within ovaries (Smith et al., 1999). Many studies of the actions of MMPs and TIMPs within ovaries have concentrated on their functions during the periovulatory period (Hagglund et al., 1999), but little is known about their expression and control throughout follicular development. Vitamin C deficiency has been associated with premature rupture of placental membranes. Addition of ascorbic acid to cultured human amnion cells resulted in a decrease in MMP activity (Pfeffer et al., 1998), which indicates that ascorbic acid may play a role in the control of these enzymes.

Although there is much information on the role of ascorbic acid during formation of corpora lutea, little is known about its role during follicular growth and development. In the present study the role of ascorbic acid during follicular growth and development was studied using an isolated follicle culture system. The culture system used allows the growth of preantral follicles through to Graafian stages and the oocytes obtained can be fertilized and live young produced (Spears et al., 1994). The culture system closely mimics growth in vivo and is therefore a highly physiological model.

\section{Materials and Methods}

\section{Animals}

$\mathrm{C} 57 \mathrm{Bl} / 6 \times \mathrm{CBA} / \mathrm{Ca} \mathrm{F} 1$ female mice aged 21-25 days were housed in an environmentally controlled room on a $14 \mathrm{~h}$ light:10 h dark photoperoid. Food and water were available ad libitum.

\section{Follicle isolation and culture}

The mice were killed by cervical dislocation and their ovaries were removed and placed on watch glasses containing Leibovitz L-15 medium (Gibco-BRL, Renfrew) supplemented with $3 \mathrm{mg}$ BSA $\mathrm{ml}^{-1}$ (Fraction V; Sigma Chemical Co, Poole). Individual preantral follicles (approximately $200 \pm 20 \mu \mathrm{m}$ in diameter) were dissected manually using fine needles and allocated randomly to the ' $U$ ' shaped wells of microtitre plates (Iwaki, Tokyo) containing $30 \mu$ l $\alpha$-minimal essential medium ( $\alpha$-MEM; Gibco-BRL) overlaid with $75 \mu$ l silicone fluid (Gibco-BRL). The culture media was supplemented with 1 iu recombinant human FSH (hrFSH; Serono-Ares, Geneva) $\mathrm{ml}^{-1}, 5 \%$ mouse serum and ascorbic acid as described below. Media were prepared freshly at 2 day intervals. The $\alpha$-MEM was supplied as $1 \times$ liquid. The formulation includes ascorbic acid at a concentration of $50 \mathrm{mg} \mathrm{I}^{-1}$; however, liquid media is prepared in batches and supplied with a minimum 3 months shelf life. Therefore, it is likely that the ascorbic acid component would have decayed in the media used.

\section{Experiment 1: effects of ascorbic acid on basement membrane integrity, follicular growth and morphology}

Follicles were cultured in control media (as above) or with the addition of either 5 or $50 \mu \mathrm{g}$ L-ascorbic acid $\mathrm{ml}^{-1}$ sodium salt (Sigma) to the culture media (28 and $280 \mu \mathrm{mol}$ $\mathrm{I}^{-1}$, respectively). Ascorbic acid stock solution (5 $\mathrm{mg} \mathrm{ml}^{-1}$ ) was prepared in $\alpha-M E M$ and aliquots were stored at $-70^{\circ} \mathrm{C}$ for 1 month only. Follicles were examined once a day; the basement membrane was defined as intact where follicles maintained their three-dimensional morphology. Follicular diameter was measured using a precalibrated ocular micrometer. Data presented on follicular growth were obtained from follicles that remained intact on the final day of culture. During the first 2 days of culture, all follicles were moved to fresh wells of media. Follicles that had lost basement membrane integrity within the first 2 days of culture were discarded from the experiment (as this may have been caused by damage during dissection). Intact follicles were moved into fresh media once a day between days 3 and 6 of culture. Ruptured follicles were not moved, but instead $15 \mu \mathrm{l}$ fresh media was exchanged for $15 \mu \mathrm{l}$ spent media each day. Thirty-six follicles were allocated to each treatment group in each run of the experiment. The experiment was repeated twice, giving a total of 72 follicles per treatment.

At the end of culture, follicles from all treatments were fixed in $4 \%(\mathrm{w} / \mathrm{v})$ paraformaldehyde (Sigma, Poole) and embedded in LR White resin (Taab Laboratories, Alderton). Sections (3 $\mu \mathrm{m}$ thickness) were cut and stained with haematoxylin-eosin.

\section{Experiment 2: effects of ascorbic acid on production of oestradiol and progesterone}

Spent culture media from days 4 and 5 of culture (see Expt 1) were analysed for oestradiol and progesterone using ELISA (Biostat, Cambridge). Oestradiol was analysed in the media separately each day, whereas progesterone was analysed from the combined media of days 4 and 5. For oestradiol, the inter- and intra-assay coefficients of variation were both $\leqslant 5 \%$ and the assay sensitivity was $\leqslant 18$ pmol $\mathrm{I}^{-1}$. For progesterone, the inter- and intra-assay coefficients of variation were both $\leqslant 5 \%$ and the assay sensitivity was $\leqslant 0.48 \mathrm{nmol} \mathrm{I}^{-1}$. The data presented are from $\geqslant 25$ individual measurements from each treatment group.

\section{Experiment 3: detection of metalloproteinase and tissue inhibitor of metalloproteinases}

Gelatin zymography and reverse zymographic analyses were conducted for detection of MMP and TIMP activities, 
respectively, in cultured mouse follicles. Freshly isolated follicles, corresponding to the diameters of follicles on each day of culture, were also analysed. These results (not shown) indicated that MMP activity was detectable in follicles of a similar size to those cultured for 2 days. On the basis of these initial experiments, follicles were cultured for 2 days in the same concentrations of ascorbic acid as in Expt 1, after which they were analysed for MMP and TIMP activity.

\section{Gelatin zymographic and reverse zymographic analyses}

Gelatin zymography was conducted with $7.5 \%(\mathrm{w} / \mathrm{v})$ SDS-PAGE gels containing $1 \mathrm{mg}$ gelatin $\mathrm{ml}^{-1}$ (Sigma, St Louis, MO), under non-reducing conditions as described by Hibbs et al. (1985) and Morodomi et al. (1992). Follicles (ten follicles per sample) were dissolved directly in $20 \mu \mathrm{l}$ SDS-PAGE loading buffer (Laemmlli, 1970) without a reducing agent to avoid the possible loss of MMP and TIMP activity associated with tissue extraction from small samples. The samples were subjected to electrophoresis at room temperature $(10 \mu \mathrm{l}$ per lane). After electrophoresis, SDS was eluted from gels in four changes of buffer containing $50 \mathrm{mmol}$ Tris- $\mathrm{HCl} \mathrm{l}{ }^{-1}(\mathrm{pH} 7.5), 5 \mathrm{mmol} \mathrm{CaCl}{ }_{2} \mathrm{I}^{-1}, 5 \mu \mathrm{mol} \mathrm{ZnCl}_{2} \mathrm{I}^{-1}$, $0.02 \%(\mathrm{w} / \mathrm{v}) \mathrm{NaN}_{3}$ and $2.5 \%(\mathrm{v} / \mathrm{v})$ Triton X-100 (Sigma) for 60-90 $\mathrm{min}$ at room temperature. The gels were then incubated in the same buffer without Triton $\mathrm{X}-100$ at $37^{\circ} \mathrm{C}$ for $20 \mathrm{~h}$, stained with Coomassie brilliant blue R250 and destained in 30\% (v/v) methanol and $1 \%(\mathrm{v} / \mathrm{v})$ formic acid. Areas of MMP activity were identified as clear bands of digested gelatin. Molecular weight markers (Gibco-BRL) and purified human pro-matrix metalloproteinase 2 (MMP-2; a gift from $\mathrm{H}$. Nagase, University of Kansas) were used to determine the molecular sizes of pro- and active forms of gelatinases. The intensity of bands was determined by use of a Chemilmager 4000 Low Light Imaging System (Alpha Innotech Corp, San Leando, CA). All gelatinase activity was

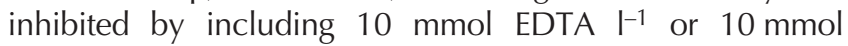
phenanthroline $\mathrm{I}^{-1}$ in the incubation buffer (data not shown).

Reverse gelatin zymography was conducted with $12 \%$ $(\mathrm{w} / \mathrm{v})$ SDS-PAGE gels containing gelatin $\left(1 \mathrm{mg} \mathrm{ml}^{-1}\right)$ under non-reducing conditions (Reverse Zymography Kit; University Technologies International Inc, Calgary). The same samples as described above $(10 \mu$ l per lane) were subjected to electrophoresis at room temperature. After electrophoresis, SDS was eluted from the gels and the gels were incubated at $37^{\circ} \mathrm{C}$ for $30 \mathrm{~h}$ as described above. Gels were stained with GelCode ${ }^{\circledR}$ Blue Stain Reagent (Pierce, Rockford, IL) and washed in water. TIMP activity was identified as dark bands of undigested gelatin. Molecular weight markers and purified recombinant ovine tissue inhibitor of metalloproteinase 1 (E. W. Mclntush and M. F. Smith, unpublished) were used to determine the molecular sizes of TIMPs. Intensity of bands was determined as described above.

In each run of the experiment, ten follicles were analysed per treatment group. The experiment was repeated three times, giving a total of 30 follicles per treatment.

\section{Experiment 4: effects of ascorbic acid on apoptosis}

Follicles were dissected as described above and assigned randomly to three groups to determine whether ascorbic acid can prevent apoptosis. Each group was cultured in 5\% $\mathrm{CO}_{2}$ at $37^{\circ} \mathrm{C}$ for $24 \mathrm{~h}$ in one of the following media: (i) $\alpha$ MEM supplemented with 1 iu hrFSH ml-1 (control group); (ii) $\alpha$-MEM supplemented with 1 iu hrFSH ml-1 and $280 \mu \mathrm{mol}$ ascorbic acid $\mathrm{I}^{-1}$ (experimental group); and (iii) $\alpha$-MEM supplemented with $5 \%$ serum, $280 \mu \mathrm{mol}$ ascorbic acid $\mathrm{ml}^{-1}$, $0.5 \mathrm{ng}$ sodium selenite $\mathrm{ml}^{-1}$ (Sigma) and $1 \mathrm{iu} \mathrm{hrFSH} \mathrm{ml}{ }^{-1}$ (positive control group, as inclusion of serum in culture media inhibits follicular degeneration through apoptosis).

\section{DNA extraction and labelling}

Genomic DNA was extracted from an average of eight follicles per culture tray using a commercial kit, according to the manufacturers' instructions (QIAmp Tissue Kit; Qiagen Ltd, Crawley). Extracted DNA was eluted in a final volume of $150 \mu \mathrm{l}$ (to maximize yield) and ethanol precipitated $\left(45 \mu \mathrm{l}\right.$ potassium acetate $\left(8 \mathrm{~mol} \mathrm{I}^{-1}\right), 400 \mu \mathrm{l}$ ethanol) and resuspended in $20 \mu \mathrm{lddH_{2 }}$ O. Extracted DNA fragments were $3^{\prime}$ end-labelled with digoxigenin using a 3 ' end labelling oligonucleotide kit (Boehringer Mannheim, Lewes) before separation by electrophoresis on a $2 \%(\mathrm{w} / \mathrm{v})$ agarose gel. The gels were Southern blotted overnight onto positively charged nylon membranes (Boehringer Mannheim), baked at $120^{\circ} \mathrm{C}$ for $30 \mathrm{~min}$ and the labelled fragments were detected using the DIG detection kit (Boehringer Mannheim) according to the manufacturers' instructions. Developed membranes were scanned using an Imaging Densitometer (Model GS-670; Bio-Rad, Hemel Hempstead) and analysed with the Molecular Analyst program (Bio-Rad). Density readings were recorded for bands corresponding to approximately 185, 370 and 555 base pairs on each lane run and mean densities were calculated. Density was calculated relative to the positive control group (iii), supplemented with serum, which was assigned an arbitrary value of 1 .

In each run of the experiment, eight follicles were analysed in each treatment group. The experiment was repeated three times, giving a total of 24 follicles per treatment.

\section{Statistical analysis}

Probability values were determined by ANOVA. Paired comparisons were made using Student's $t$ test where appropriate.

\section{Results}

\section{Experiment 1: effects of ascorbic acid on basement membrane integrity, follicular growth and morphology}

In the absence of ascorbic acid, 33\% of follicles maintained integrity of the basement membrane throughout the 

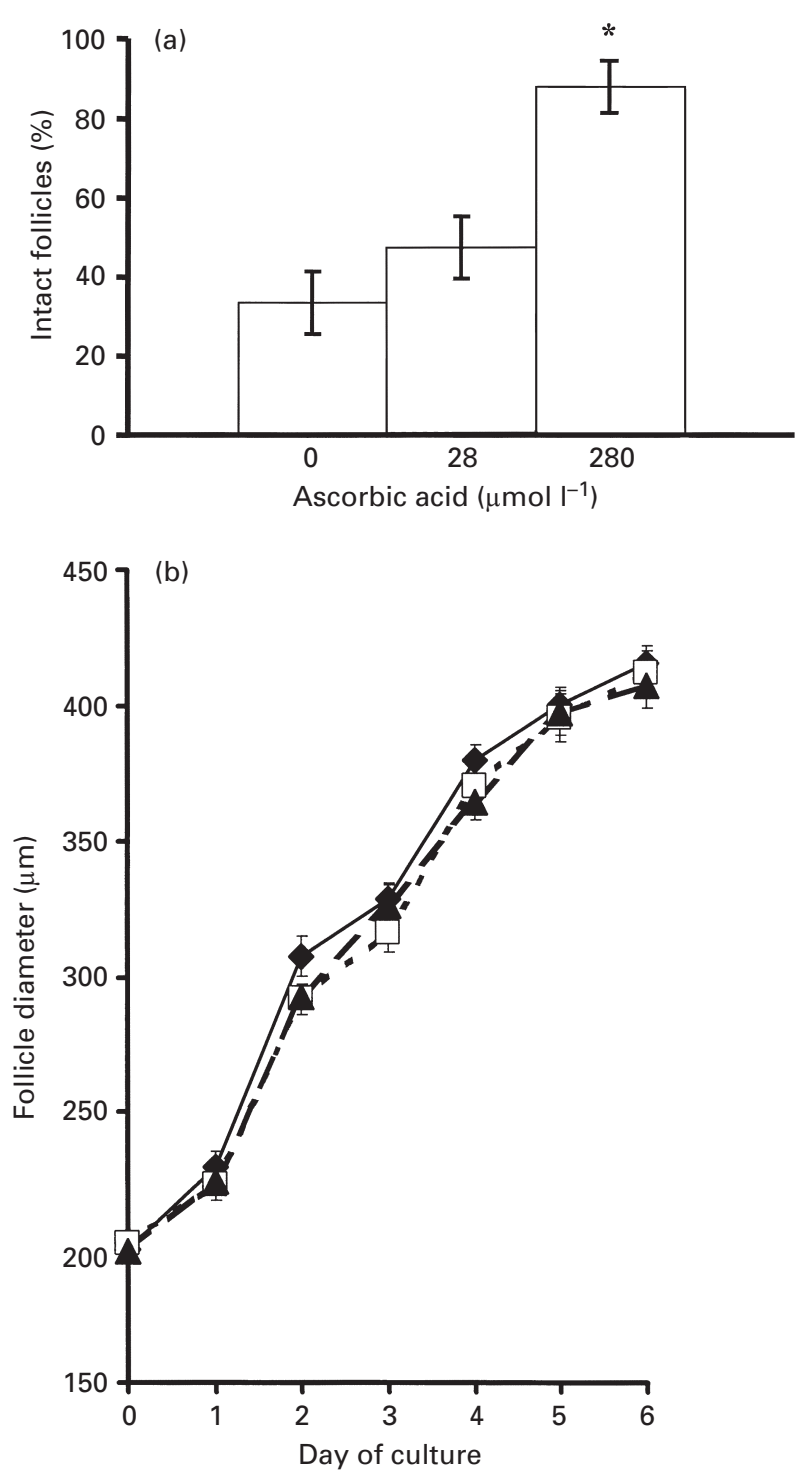

Fig. 1. (a) Percentage of mouse follicles with an intact basement membrane at the end of 6 day culture. Follicles were cultured in control media or in media supplemented with either 28 or $280 \mu \mathrm{mol}$ ascorbic acid $\mathrm{I}^{-1}$. Values are mean $\pm \operatorname{SEM}(n=72)$. *Significantly different from control value $(P<0.001)$. (b) Growth rates of mouse follicles cultured in control media $(\bullet)$ and in media supplemented with either $28(\square)$ or $280(\boldsymbol{\Lambda}) \mu \mathrm{mol}$ ascorbic acid $\mathrm{I}^{-1}$. Values are mean $\pm \operatorname{SEM}(n=72)$.

6 days of culture. A non-significant increase in the percentage of follicles remaining intact $(47 \%)$ was observed in follicles cultured in $28 \mu \mathrm{mol}$ ascorbic acid $\mathrm{I}^{-1}$. However, when follicles were cultured in $280 \mu \mathrm{mol}$ ascorbic acid $\mathrm{I}^{-1}$ there was a significant increase in the percentage of follicles remaining intact $(88 \% ; P<0.001)$ compared with controls (Fig. 1a).

Follicular growth rate was unaffected by ascorbic acid concentration. Follicles that remained intact in the control and ascorbic acid-treated groups had reached similar sizes by day 6 of culture (Fig. 1b). Histological examination of

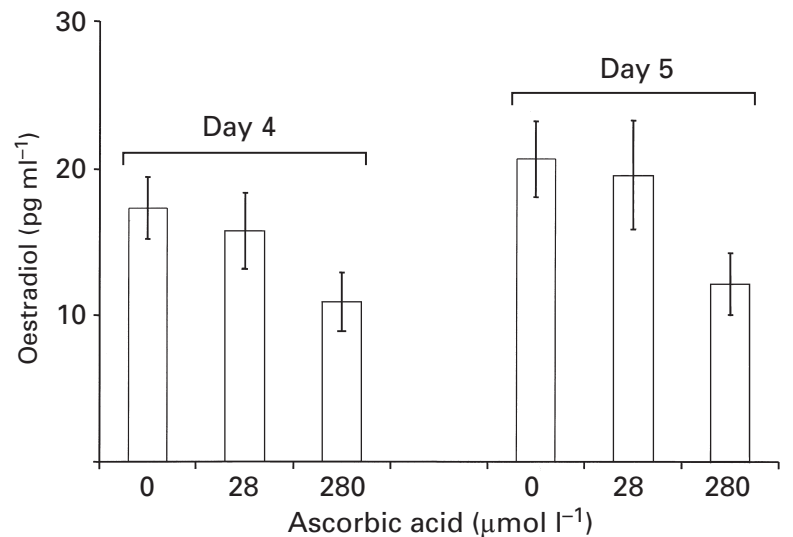

Fig. 2. Production of oestradiol by mouse follicles on days 4 and 5 of culture. Mouse follicles were cultured in media containing 0 , 28 or $280 \mu \mathrm{mol}$ ascorbic acid $\mathrm{I}^{-1}$. Data are mean $\pm \operatorname{SEM}(n \geqslant 25)$.

follicles at the end of culture showed that intact follicles were of similar size and had large antral cavities regardless of treatment (data not shown).

\section{Experiment 2: effects of ascorbic acid on oestradiol and progesterone production}

Oestradiol analysis was performed on media collected on days 4 and 5 of culture. Media were collected from both intact follicles and those that had lost their basement membrane integrity. The results indicate that oestradiol production increased between day 4 and day 5 in all treatments. Addition of ascorbic acid to the media reduced the production of oestradiol whether or not follicles had maintained basement membrane integrity, although this decrease was not significant (Fig. 2). Progesterone production was not detected in any group.

\section{Experiment 3: detection of metalloproteinase and tissue inhibitor of metalloproteinase}

The primary gelatinolytic bands $\left(M_{r} 62000\right.$ and 72000$)$ corresponded to the pro- and active forms of MMP-2 (gelatinase A) and comigrated with the pro- and active forms of recombinant human MMP-2. The larger gelatinolytic band (pro-MMP-2) was the predominant form present within mouse follicles. Addition of ascorbic acid at $280 \mu \mathrm{mol} \mathrm{I}^{-1}$ resulted in a small but significant increase $(P<0.01)$ in TIMP-1 activity, whereas $28 \mu \mathrm{mol}$ ascorbic acid $\mathrm{I}^{-1}$ did not. MMP-2 activity increased at the higher concentration but the increase was not significant (Fig. 3).

\section{Experiment 4: effects of ascorbic acid on apoptosis}

Control follicles grown in the absence of serum showed high levels of apoptosis (measured as the degree of nuclear DNA laddering). Addition of ascorbic acid to the serumfree media (experimental group) significantly reduced the incidence of DNA fragmentation $(P<0.05)$ to nearer the values of the positive control group, which also contained serum and selenium (Fig. 4). 

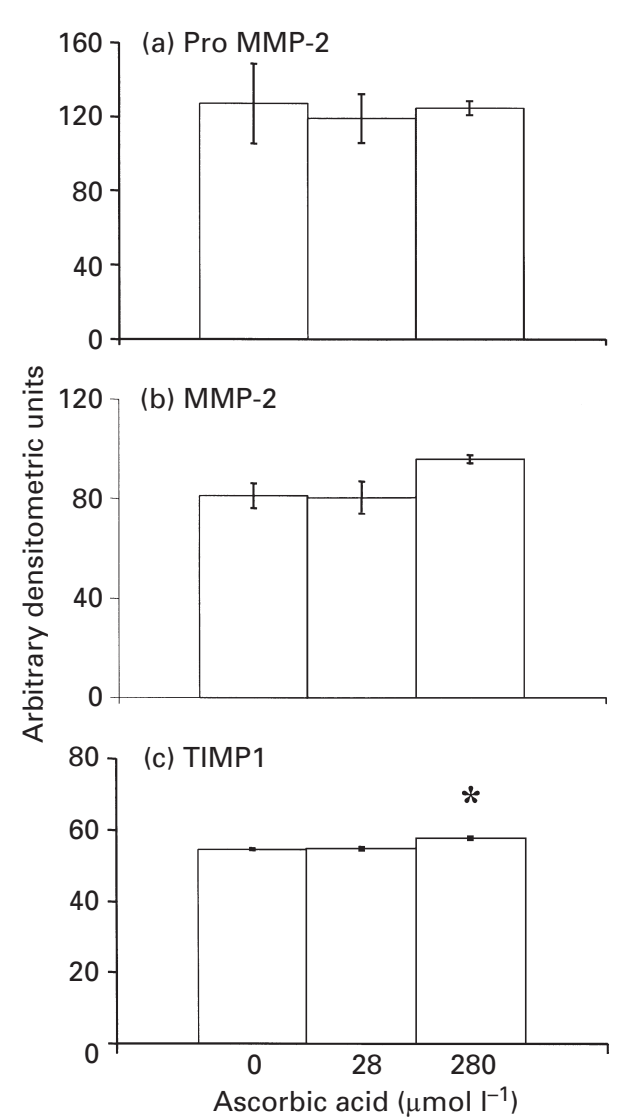

Fig. 3. Effect of ascorbic acid concentration on (a) gelatinolytic pro-matrix metalloproteinase 2 (MMP-2), (b) activated MMP-2 and (c) tissue inhibitor of metalloproteinase 1 activities in mouse follicles. Values were assigned arbitrary densitrometric units. Values are mean $\pm \operatorname{SEM}(n=30)$. *Value is significantly different from control $(P<0.01)$.

\section{Discussion}

In common with other endocrine tissues, the ovaries are sites of ascorbic acid accumulation, which fluctuates in response to stimuli such as $\mathrm{LH}$, cyclic AMP and prostaglandins. Most studies have concentrated on the well-known effects of ascorbic acid on steroidogenesis in response to these factors (Sanyal and Datta, 1979). However, it has been suggested that the high ascorbic acid content measured within ovarian tissue is in excess of that required solely for steroidogenesis. As the ovaries are sites of intensive tissue remodelling, ascorbic acid is probably required as a co-factor in collagen production (Luck et al., 1995). Much attention has been paid to the ability of ascorbic acid to act as an antioxidant (Padh, 1991); as both tissue remodelling and steroidogenesis are processes that produce reactive oxygen species, it is likely that ascorbic acid serves this function within the ovaries. The results of the present study indicate that the multi-functional activities of ascorbic acid contribute to follicular development.

The hormonal influences that affect follicular growth and development have been well documented but little is known about the physical processes that occur throughout the growth phase. During follicular growth and expansion there is rapid production of the basal lamina that separates the thecal and granulosa compartments. This has been estimated as a $3 \times 10^{4}$ times increase in mice (Gosden et al., 1993). In the in vitro system described in the present study, murine follicles grew from approximately $200 \mu \mathrm{m}$ to approximately $415 \mu \mathrm{m}$ in diameter during culture for 6 days, resulting in a 4.3 times increase in follicular surface area. Although ascorbic acid had no effect on the growth rate or morphology of the follicles, there was a marked increase in the percentage of follicles able to maintain basement membrane integrity. Without ascorbic acid, only $33 \%$ of the follicles had retained an intact membrane after 6 days in culture compared with $88 \%$ when the medium was supplemented with $280 \mu \mathrm{mol}$ ascorbic acid $\mathrm{I}^{-1}$. Although this is a higher concentration than that found commonly in human serum, it correlates reasonably well with the high concentrations of ascorbic acid found in human follicular fluid (Luck et al., 1995). These results are in good agreement with a recent report by Rose et al. (1999), in which addition of selenium and ascorbic acid also increased the percentage of follicles able to maintain their spherical morphology when cultured in vitro. In the culture system used in the present study, no selenium was added to the media and therefore the effect seen can be attributed solely to the addition of ascorbic acid. A very early study with scorbutic guinea pigs noted that these animals were anovulatory and a marked degeneration of the follicular wall was observed (Kramer et al., 1933). A major component of the follicular basal lamina is collagen IV, which both granulosa and theca cells can produce in vitro (Rodgers et al., 1995; Zhao and Luck, 1995). Ascorbic acid is known to promote collagen synthesis, both at the level of the gene, and as a co-factor in the secretion and stabilization of the protein (Pinnell, 1985). Therefore, it could be assumed that the growing follicle would have a high requirement for ascorbic acid if it is to produce sufficient basal lamina components to maintain expansion of this membrane during development. The results presented here support this idea. There are also unpublished data (V. Srsen and N. Spears, unpublished) which show that follicles grown in the presence of ascorbic acid require a more stringent permeabilization treatment before fixation, providing further evidence for a role of ascorbic acid in basal lamina formation and stabilization. Rodgers et al. (1998) reported that in bovine follicles the distribution of the collagen IV chains within the basal lamina changes composition during follicular development. As ascorbic acid was present in the media throughout the culture period, it was not possible to determine whether it was required at all stages of development or, for example, only during pre- or post-antrum formation.

Extracellular matrix components are constantly remodelled by the action of extracellular proteases, mainly MMPs and TIMPs. As such, MMPs and TIMPs are obvious candidates for modulating the ovarian follicle basement 
(a)

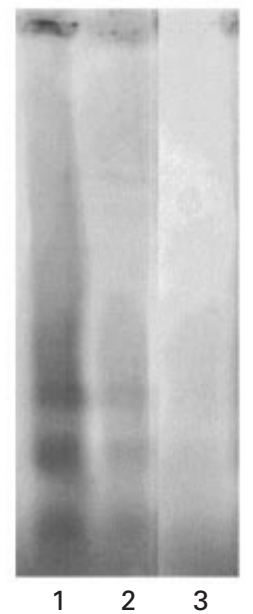

(b)

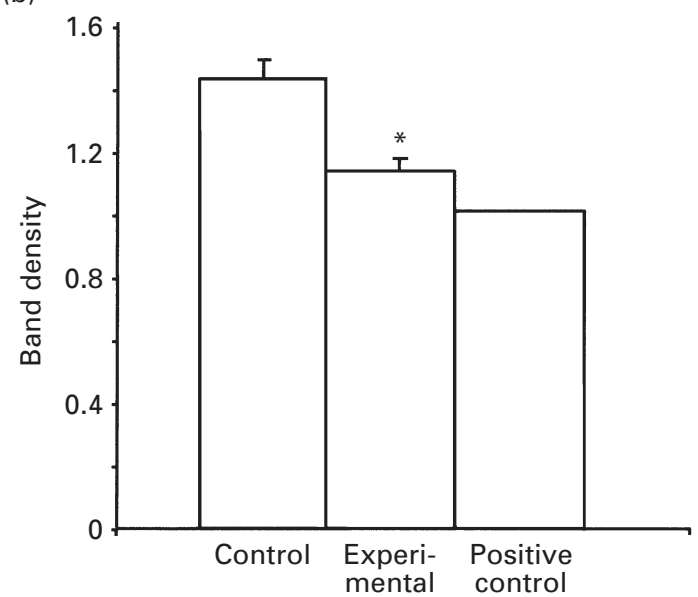

Fig. 4. (a) Representative gel of mouse follicles showing laddering of DNA into approximately 185 bp multiples. Lane 1: control group (cultured in the absence of serum). Lane 2: experimental group (cultured in the absence of serum but with the addition of $280 \mu \mathrm{mol}$ ascorbic acid $\left.\right|^{-1}$ ). Lane 3: positive control group (cultured in the presence of serum, $280 \mu \mathrm{mol}$ ascorbic acid $\mathrm{I}^{-1}$ and $5 \mu \mathrm{g}$ selenium $\mathrm{ml}^{-1}$ ). (b) Densities of apoptotic bands in control and experimental groups, calculated relative to the positive control group, which was assigned an arbitrary value of 1 . Values are mean $\pm \operatorname{SEM}(n=24) .{ }^{*}$ Value is significantly different from control $(P<0.05)$.

membrane. The collagenous component of the ovarian stroma includes interstitial collagen types I and III, whereas collagen type IV is the collagenous component of the basement membrane. Collagens can be degraded by MMP-2, which is activated during structural luteolysis, concurrent with a marked depletion in ascorbic acid (Endo et al., 1993). In humans, vitamin $C$ deficiency has been associated with increased rupture of placental membranes and addition of ascorbic acid to cultured human amnion cells decreased MMP-2 expression and activity (Pfeffer et al., 1998). These reports indicate that ascorbic acid influences the actions of MMPs. In the present study, the proand active forms of MMP-2 (gelatinase A) were detected within cultured mouse follicles collected on day 2, just before the period during which most cultured follicles began to rupture. Although similar MMP-2 and TIMP-1 activities were present in control follicles and in those cultured with the lower concentration of ascorbic acid, a significant increase in TIMP-1 was observed at the higher concentration of ascorbic acid used; this is the same treatment in which a significantly higher percentage of follicles had the ability to maintain basement membrane integrity. TIMP and MMP activities frequently increase simultaneously (Murphy et al., 1985): in this instance there was a concomitant increase in the active form of MMP-2, although this increase was not significant. Although the results of the present study add further evidence for a role of ascorbic acid in mediating MMP activity within growing follicles, it seems most likely to be acting through a mechanism that allows both formation and expansion of the basement membrane, and hence requires both MMPs and TIMPs.

Absence of serum from the culture media induced apoptosis in the preantral follicles within a short period (24 h of culture), as detected by DNA laddering. Addition of ascorbic acid to the serum-free media reduced the degree of apoptosis within these follicles. Tilly and Tilly (1995) described a similar effect of antioxidants (including ascorbic acid) in short term cultures of rat antral follicles. These authors concluded that oxidative stress could play a role in follicular atresia by inducing an apoptotic mechanism. Ascorbic acid accumulation has been described within follicles at all stages of development; in the small follicles of buffalo (Meur et al., 1999), Graafian follicles of humans (Paszkowski and Clarke, 1999) and, in the present study, in late preantral follicles of mice. Granulosa cells, under the influence of $\mathrm{FSH}$, take up ascorbic acid actively (Berhman et al., 1996) and although this is consistent with the idea of ascorbic acid being required as a co-factor in collagen synthesis and hence basal lamina expansion, it is likely that ascorbic acid also functions as an antioxidant preventing cell death. At the late preantral stage of development, follicles acquire responsiveness to gonadotrophins and develop rapidly; therefore it is feasible that an ability to accumulate ascorbic acid confers an advantage to a follicle and promotes survival.

In the present study ascorbic acid did not affect production of oestradiol. This finding is in contrast to other systems, in which addition of ascorbic acid in vitro adversely affected aromatase activity through alteration of $\mathrm{pH}$ (Milewich et al., 1981). High concentrations of ascorbic acid are inhibitory to cholesterol side chain cleavage (Pintauro and Bergan, 1982), which subsequently affects androgen production and directly decreases aromatase activity (Sanyal and Datta, 1979; Tsuji et al., 1989). The 
effect of ascorbic acid on progesterone could not be determined, as progesterone concentrations were not measurable in any media in the present study. However, the lack of progesterone production shows that the granulosa cells in follicles unable to maintain their basement membrane had not undergone premature luteinization. The relationship between ascorbic acid and oestradiol appears complex. Circulating ascorbic acid concentrations are low in woman using oral contraceptives, perhaps through an inhibitory effect of oestradiol on ascorbic acid uptake by the intestine (Kuo and Lin, 1998). When high doses of ascorbic acid were administered exogenously to pregnant women, oestradiol production increased, resulting in abortion (Samborskaia and Ferdman, 1966). However, Graafian follicles, which have high concentrations of oestradiol in the follicular fluid, are the sites of ascorbic acid accumulation (Paszkowski and Clarke, 1999). High concentrations of oestradiol are required to inhibit the oxidation of low-density lipoproteins (LDL) in vitro. However, in the presence of ascorbic acid, concentrations of oestradiol close to physiological concentrations can also protect LDLs from oxidation (Huang et al., 1999). Although the effects of ascorbic acid on oestradiol may be tissue specific, further investigations are needed to determine the effects of ascorbic acid on oestradiol production within follicles.

In conclusion, ascorbic acid greatly increased the percentage of follicles able to maintain their basement membrane in vitro but did not affect growth rate. Ascorbic acid also increased the production of MMP-2 and TIMP-1 by the cultured follicles, which implicates this vitamin in modulating MMP remodelling of the basement membrane. Ascorbic acid reduced the degree of apoptosis within follicles subjected to oxidative stress (serum-free cultures) indicating that accumulation of ascorbic acid would be advantageous for survival. The effects of ascorbic acid on oestradiol production require further investigation.

The authors would like to thank V. Allison and R. Smith for expert technical assistance. They are grateful to V. Srsen for translation of references and $U$. Rose for advice on the concentrations of ascorbic acid used to supplement culture media. The recombinant FSH was a gift from Serono-Ares, Geneva, Switzerland. N. Spears is a Royal Society University Research Fellow and the Wellcome Trust supported this study.

\section{References}

Behrman HR, Preston SL, Aten RF, Rinaudo P and Zreik TG (1996) Hormone induction of ascorbic acid transport in immature granulosa cells Endocrinology 10 4316-4321

Byrd JA, Pardue SL and Hargis BM (1993) Effect of ascorbate on luteinizing hormone stimulated progesterone biosynthesis in chicken granulosa cells in vitro. Comparative Biochemistry and Physiology C 104 279-281

Deane HW (1952) Histochemical observation on the ovary and oviduct of the albino rat during the estrus cycle American Journal of Anatomy $\mathbf{9 1}$ 363-413

Endo T, Aten RF, Wang F and Behrman HR (1993) Co-ordinate induction and activation of metalloproteinase and ascorbate depletion in structural luteolysis Endocrinology 133 690-698

Espey LL and Coons PJ (1976) Factors which influence ovulatory degradation of rabbit ovarian follicles Biology of Reproduction 14 233-245

Gosden RG, Boland NI, Spears N, Murray AA, Chapman M, Wade JC, Zhody NI and Brown N (1993) The biology and technology of follicular oocyte development in vitro. Reproductive Medicine Review 2 129-152

Hagglund AC, Ny A, Leonardsson G and Ny T (1999) Regulation and localization of matrix metalloproteinases and tissue inhibitors of metalloproteinases in the mouse ovary during gonadotrophin-induced ovulation Endocrinology 140 4351-4358

Hibbs MS, Hasty KA, Seyer JM, Kang AH and Mainardi CL (1985) Biochemical and immunological characterization of the secreted forms of human neutrophil gelatinase Journal of Biological Chemistry 260 2493-2500

Huang M, Li J, Teoh H and Man RY (1999) Low concentrations of 17 beta-estradiol reduce oxidative modification of low-density lipoproteins in the presence of vitamin C and vitamin E Free Radical Biology and Medicine 27 438-441

Igarashi M (1977) Augmentative effect of ascorbic acid upon induction of human ovulation in clomiphene-ineffective anovulatory women International Journal of Fertility 22 168-173

Kramer MM, Harman MT and Brill AK (1933) Disturbances of reproduction and ovarian changes in the guinea-pig in relation to vitamin $\mathrm{C}$ deficiency American Journal of Physiology 106 611-622

Kuo SM and Lin CP (1998) 17beta-estradiol inhibition of ascorbic acid accumulation in human intestinal Caco-2 cells European Journal of Pharmacology 361 253-259

Laemmli UK (1970) Cleavage of structural proteins during the assembly of the bacteriophage T4 Nature 220 680-685

Luck MR and Junglas B (1987) Catecholamines and ascorbic acid as stimulators of bovine ovarian oxytocin secretion Journal of Endocrinology 114 423-430

Luck MR, Jeyaseelan I and Scholes RA (1995) Ascorbic acid and fertility Biology of Reproduction 52 262-266

Meur SK, Sanwal PC and Yadav MC (1999) Ascorbic acid in buffalo ovary in relation to oestrus cyle Indian Journal of Biochemistry and Biophysics 36 134-135

Milewich L, Chen GT, MacDonald PC and Peterson JA (1981) Ascorbic acid inhibition of aromatase activity in human placenta tissue Journal of Steroid Biochemistry 14 185-193

Morodomi T, Ogata Y, Sasaguri Y, Morimatsu M and Nagase H (1992) Purification and characterization of matrix metalloproteinase 9 from U937 monocytic leukaemia and HT1080 fibrosarcoma cells Biochemical Journal 285 603-611

Murphy G, Reynolds J and Werb Z (1985) Biosynthesis of tissue inhibitor of metalloproteinases by human fibroblasts in culture. Stimulation by 12-O tetradecanoylphorbol 13-acetate and interleukin 1 in parallel with collagenase Journal of Biological Chemistry 260 3079-3083

Padh H (1991) Vitamin C: newer insights into its biochemical functions Nutrition Reviews 49 65-70

Parlow AF (1958) A rapid bioassay method for $\mathrm{LH}$ and factors stimulating LH secretion Federation Proceedings 85 501-520

Paszkowski T and Clarke RN (1999) The Graafian follicle is the site of L-ascorbate accumulation Journal of Assisted Reproduction and Genetics 16 41-45

Pfeffer F, Casenueva E, Kamar J, Guerra A, Perichart $O$ and VadilloOrtega F (1998) Modulation of 72-kilodalton type IV collagenase (matrix metalloproteinase-2) by ascorbic acid in cultured human amnion-derived cells Biology of Reproduction 59 326-329

Phillips PH, Lardy HA, Boyer PD and Werner GM (1941) The relationship of ascorbic acid to reproduction in the cow Journal of Dairy Science 24 153-158

Pinnell SR (1985) Regulation of collagen synthesis by ascorbic acid: a review Yale Journal of Biology and Medicine 58 553-559

Pintauro SJ and Bergan JG (1982) Effects of ascorbic acid on in-vitro steroidogenesis in guinea pigs Journal of Nutrition 112 584-591

Rodgers HF, Lavranos TC, Vella CA and Rodgers RJ (1995) Basal lamina 
and other extracellular matrix produced by bovine granulosa cells in anchorage-independent culture Tissue Research 282 463-471

Rodgers HF, Irvine CM, van Wezel IL, Lavranos TC, Luck MR, Sado Y, Ninomiya Y and Rodgers RJ (1998) Distribution of the alpha6 chains of type IV collagen in bovine follicles Biology of Reproduction $\mathbf{5 9}$ $1334-1341$

Rose UM, Hanssen RG and Koosterboer HJ (1999) Development and characterization of an in vitro ovulation model using mouse ovarian follicles Biology of Reproduction 61 503-511

Samborskaia EP and Ferdman TD (1966) Mechanism of abortion induced by ascorbic acid Biulletin Eksperimentalnoi Biologii I Meditsiny 62 96-98

Sanyal S and Datta S (1979) Effect of ascorbic acid in in vitro rat adrenal and ovarian steroidogenesis Indian Journal of Experimental Biology 17 86-88

Smith MF, McIntush EW, Ricke WA, Kojima FN and Smith GW (1999 Regulation of ovarian extracellular matrix remodelling by metalloproteinase and their tissue inhibitors: effects on follicular development ovulation and luteal function Journal of Reproduction and Fertility Supplement 54 367-381

Spears N, Boland NI, Murray AA and Gosden RG (1994) Mouse oocytes derived from in vitro grown primary follicles are fertile Human Reproduction 9 527-532

Stansfield DA and Flint AP (1967) The entry of ascorbic acid into the corpus luteum in-vivo and in-vitro and the effect of luteinising hormone Journal of Endocrinology 39 27-35

Tilly JL and Tilly KI (1995) Inhibitors of oxidative stress mimic the ability of follicle-stimulating hormone to suppress apoptosis in cultured rat ovarian follicles Endocrinology 136 242-252

Tsuji M, Ito Y, Terada N and Mori H (1989) Ovarian aromatase activity in scorbutic mutant rats unable to synthesize ascorbic acid Acta Endocrinologica (Copenhagen) 121 595-602

Zhao Y and Luck MR (1995) Gene expression and protein distribution of collagen, fibronectin and laminin in bovine follicles and corpora lutea Journal of Reproduction and Fertility 104 115-123

Received 21 March 2000.

Accepted 5 July 2000 